\title{
Stronger evidence is needed before accepting that cannabis plays an important role in the aetiology of schizophrenia
} in the population

\author{
Suzanne H. Gage ${ }^{1,2}$, Stanley Zammit ${ }^{1,3}$ and Matthew Hickman ${ }^{1 *}$
}

Addresses: ${ }^{1}$ School of Social and Community Medicine, University of Bristol, Canynge Hall, 39 Whatley Road, Bristol, BS8 1TU; ${ }^{2} \mathrm{MRC}$ Centre for Causal Analyses in Translational Epidemiology, Oakfield House 15-23 Oakfield Grove, Bristol, BS8 2BN; ${ }^{3}$ Institute of Psychological Medicine and Clinical Neurosciences, MRC Centre for Neuropsychiatric Genetics and Genomics, Cardiff University, Henry Wellcome Building, Heath Park, Cardiff, CF14 4XN

* Corresponding author: Matthew Hickman (matthew.hickman@bristol.ac.uk)

Fl000 Medicine Reports 2013, 5:2 (doi:10.3410/M5-2)

This is an open-access article distributed under the terms of the Creative Commons Attribution-Non Commercial License (http://creativecommons.org/licenses/by-nc/3.0/legalcode), which permits unrestricted use, distribution, and reproduction in any medium, provided the original work is properly cited. You may not use this work for commercial purposes.

The electronic version of this article is the complete one and can be found at: http://fl000.com/prime/reports/m/5/2

\begin{abstract}
Schizophrenia is a debilitating but poorly understood condition with very few known modifiable risk factors. Cannabis use can acutely induce psychotic experiences, but its causal relationship to schizophrenia is less well understood. Longitudinal cohort studies suggest that the association between cannabis and psychotic outcomes is not due to chance or reverse causation. However, the association could be due to bias or residual confounding. Methods that can test alternative explanations in greater depth are required. This is especially important as ecological studies have found little association between the increase in cannabis use over recent decades and incidence of psychotic disorders; public health models suggest that cannabis use may need to be treated and prevented in many thousands of users in order to prevent one case of schizophrenia. We believe that, while such uncertainty exists, there is a scientific duty to continue to investigate the role of cannabis in the aetiology of schizophrenia and that the policy case for considering cannabis exposure as a critical target for preventing schizophrenia is yet to be made. However, due to other evidence of the harms of cannabis use, this should not affect the public health message that cannabis can be harmful and that cannabis dependence should be prevented.
\end{abstract}

\section{Introduction}

Schizophrenia is a serious illness associated with substantial loss of quality of life, social and economic problems, co-morbidity and premature mortality, and the need to improve primary prevention is paramount $[1,2]$. Aetiology of schizophrenia offers few clearly modifiable factors: rates are higher in those with family history of psychiatric illness, men, and vary by migrant status and ethnic group, urbanicity and economic status [1-4]. Cannabis can cause acute transient, usually mild psychotic experiences while intoxicated, with minimal functional impairment directly following use [5], and can worsen the course of illness in people with schizophrenia [6]. The critical question, however, is whether cannabis use increases the risk of more severe and prolonged psychotic states such as schizophrenia, aside from these intoxication effects. If true, this could have important clinical and public health implications, as cannabis appears to be more readily modifiable than other factors for schizophrenia.

We consider the strength of the evidence for a causal relationship between cannabis use and chronic psychotic disorders, including schizophrenia, and how important 
cannabis might be for public health and policy in terms of a target for prevention of these disorders.

\section{Cannabis and psychosis}

Evidence has been present for some years that individuals who use cannabis have an increased risk of psychotic outcomes. A systematic review of the longitudinal studies [7] found consistent empirical evidence that individuals who used cannabis had an increased risk of psychotic outcomes, and studies published since have also reported results consistent with these findings $[8,9]$. Although this suggests that the association is unlikely to be due to chance and due to the longitudinal nature of the studies, reverse causation (i.e. where the perceived cause-effect relationship may be reversed) is also unlikely - bias and residual confounding remain plausible explanations.

\section{Considering confounding and bias}

There are a variety of types of bias that could distort the relationship between cannabis and psychosis (as those subjects with both factors would be much more likely to drop out). Follow up bias, whereby people who use cannabis and people with psychotic symptoms may both be more likely to drop out of a cohort study, would be expected to lead to an underestimate of the relationship between cannabis and psychosis. Non-differential misclassification (i.e. where errors in the measurement of cannabis are unrelated to the outcome) of cannabis exposure would also dilute any relationship. Few of the studies, however, examine schizophrenia as an outcome, and conclusions regarding the effects of cannabis on this disorder are based primarily on studies of psychotic experiences [10]. Psychotic experiences occur much more commonly in the population than disorders such as schizophrenia and, in the majority of cases, do not lead to the distress or impairment that are universal characteristics of psychotic disorders. There are a number of lines of evidence indicating that psychosis exists on a continuum, and it seems reasonable to assume that risk factors for psychotic experiences in the general population will also be associated with risk for psychotic disorders. However, given the clear differences that exist between the epidemiology of psychotic experiences and that of schizophrenia, it may be invalid to infer the magnitude of the relationship between cannabis and schizophrenia from studies examining psychotic experiences as their outcome. Perhaps more importantly, however, acute psychotic episodes caused by intoxication effects may also bias findings. Not all longitudinal studies to date have considered intoxication effects, and where participants are using cannabis on a daily or regular basis, it seems unlikely that psychotic events induced by intoxication can be teased out at all. Studies of psychotic experiences in samples of the general population are likely to be particularly prone to outcomes resulting from intoxication effects compared with studies of clinical disorders diagnosed after periods of hospital admission, where such intoxication effects can be more readily excluded.

The main limitation to interpreting the association between cannabis use and schizophrenia has been that of residual confounding [10]. The cohort studies reviewed by Moore et al. [7] differ quite dramatically in the number and quality of confounders that are adjusted for. The studies that adjust for a large number of confounders find the point estimates attenuate to a greater degree (suggesting the size of the effect is smaller) than those that adjust for very few confounders. This suggests that there may still be residual confounding distorting the true relationship between cannabis use and psychotic symptoms. For example, few studies adjust for tobacco use, and other illicit drug use is only sporadically accounted for. It is also worth considering that drug taking of any kind could be associated with personality type or early-life and family adversity, which may be risk factors for psychosis, rather than the biological effect of any drug per se. Strategies attempting to address problems of confounding in observational studies include use of siblings as controls [11], use of statistical modelling methods, such as fixed-effects or self-controlled case series, which control for unmeasured time-invariant confounding $[12,13]$ or use of mendelian randomisation (where genetic variants provide an unconfounded measure of exposure) and instrumental variable techniques if suitable measures become available $[14,15]$.

\section{Is the evidence good enough?}

Observational epidemiology can suffer from spurious findings: bias, reverse causation or residual confounding have led to consistent results in observational studies, which are then shown to be false when investigated experimentally $[16,17]$. It is therefore important to consider evidence from other sources to complement (or test) observational epidemiological findings. One source of evidence that does not support a causal relationship between cannabis use and schizophrenia is the comparison of cannabis use and schizophrenia incidence over time. There is evidence that cannabis use in many developed countries has increased greatly over the past 40 years [18-20]. For example, in the UK, cannabis use has risen 10-20 fold since the 1970s [19]. However, recent data on new admissions for schizophrenia have shown no increase at all $[18,21]$; indeed, there is a suggestion of a downward trend in diagnoses.

A similar pattern of increasing cannabis use but stable incidence of schizophrenia is also seen in Australia [18]. 
However, these data are ecological, and therefore it is possible that relationships are due to different sub-populations driving the variations, or that improvements in mental health care or changes in other risk factors have reduced the risk of schizophrenia over this same time period (and confounded the relationship between cannabis and schizophrenia). The point is that there does not seem to be a simple observable relationship between cannabis exposure and schizophrenia incidence that would support substantial investment in a public health campaign to prevent schizophrenia through preventing cannabis use.

\section{Does uncertainty in evidence matter?}

Policymakers and clinicians invoke the "precautionary principle" to justify the importance of controlling and preventing cannabis use in relation to schizophrenia [22]. Even though it is not currently possible to be certain whether or not cannabis causes schizophrenia, there is a strong argument to encourage people not to use this drug [23]. For example, cannabis is most commonly used in the UK by smoking it with tobacco, which means it poses the same dangers that tobacco use does. As well as this, frequent cannabis use can lead to dependence and has been associated with impairments in educational, occupational and social attainments [9]. Nonetheless, although cannabis is a modifiable factor, estimates of the number of people that need to stop heavy cannabis use to prevent one case of schizophrenia are in the thousands (e.g. between 3000 and 5000 heavy cannabis users and between 10,000 and 20,000 young men and women with any cannabis use, respectively) [24]. Furthermore, current interventions to reduce dependence are of limited effectiveness, so for an intervention that was $20 \%$ effective, the "number needed to treat" would be in the tens of thousands. In terms of a public health message, there is no doubt that the potential harms from cannabis use should be highlighted, but even a large-scale campaign to reduce cannabis use may have a limited effect on reducing rates of schizophrenia.

It is possible that some individuals are at particularly high risk of developing a psychotic illness after using cannabis, and targeted interventions to reduce cannabis use in such individuals might be more successful than an en masse approach. A number of studies have tried to identify such high-risk individuals. For example, a report finding that the effect of cannabis on psychosis risk was strongly conditional on variation within the COMT gene [25] received a lot of interest amongst the scientific community, but this initial finding has not been directly replicated by any studies since [26-28]. It is perhaps in this area of high-risk subgroups in particular where evidence regarding the aetiological role of cannabis in schizophrenia is least robust.
Interest is also focusing on the strength of cannabis and whether different varieties of cannabis are more psychomimetic than others [29]. Whilst the delta-9tetrahydrocannabinol (THC) component of cannabis can induce transient psychotic experiences [5], recent evidence suggests another component, cannabidiol (CBD), may actually be antipsychotic [30]. The strains of skunk (the cannabis most often used in the UK) that are most commonly available have very low CBD and higher levels of THC [31], and one study to date suggests that skunk may be associated with higher risk of schizophrenia than other forms of this drug [29]. However, the psychotogenic effects of compounds with different relative amounts of THC and CBD have not been wholly consistent in other studies [32,33].

Robust evidence is required to support the hypotheses that specific sub-groups are at particularly high risk of psychosis following cannabis use, or that differential effects of the THC and CBD components of cannabis are important in determining risk for schizophrenia. Assumptions based on weak evidence, or based on theoretical research paradigms, may be misleading. For example, as a strategy to reduce the harm related to tobacco use, individuals were encouraged to switch to "low tar" cigarettes with increased filter ventilation because machine-based research showed them to be less harmful than "high tar" varieties [34]. However, in practice, smokers responded by compensating for this: some blocked the filter with their fingers, and increased strength and frequency of inhalations, resulting in no health benefits from switching $[35,36]$.

From a research perspective, research programmes directed at examining biological or psychological mechanisms by which cannabis might play an aetiological role in schizophrenia, or aimed at testing interventions based on such mechanisms are often costly to implement. Guidance of such programmes is dependent on high-quality evidence to increase the likelihood they will be cost-effective initiatives. At the moment, such evidence does not exist in the case for cannabis causing psychosis.

\section{Conclusions}

Despite consistent evidence that individuals who use cannabis have an increased risk of psychotic outcomes, it should not be surprising that the role of cannabis in the aetiology of schizophrenia remains uncertain given the limits of observational epidemiology. In particular, the extent to which the incidence of schizophrenia will be altered by reducing cannabis use or changing the type of cannabis used in the population, or in specific subgroups, remains unclear. 
Whilst the evidence is "good enough" to continue promoting the public health message that cannabis is harmful, and that it may increase risk of schizophrenia, it is important not to overstate the evidence: the majority of people who use cannabis will not develop schizophrenia, and it appears that a considerable number of heavy cannabis users would need to be prevented in order to prevent one case of schizophrenia. From a scientific perspective, however, the extent to which use of cannabis leads to an increased incidence of schizophrenia, independently of confounding characteristics and separate from effects of chronic intoxication, remains uncertain. Whether preventing cannabis use will have any substantial impact on preventing psychotic disorders in the population, or within specific subgroups at risk, is yet to be adequately determined.

\section{Abbreviations}

CBD, cannabidiol; THC, delta-9-tetrahydrocannabinol.

\section{Disclosures}

The authors declare that they have no disclosures.

\section{References}

I. McGrath J, Saha S, Chant D, Welham J: Schizophrenia: a concise overview of incidence, prevalence, and mortality. Epidemiol Rev 2008, 30:67-76.

\section{FlOOOPrime}

\section{RECOMMENDED}

2. Murray RM, Jones PB, Susser ES, Van Os J, Cannon M: The Epidemiology of Schizophrenia. Cambridge: Cambridge University Press; 2003.

3. Pedersen $C B$, Mortensen PB: Family history, place and season of birth as risk factors for schizophrenia in Denmark: a replication and reanalysis. BrJ Psychiatry 200I, I79:46-52.

\section{FlOOOPrime}

4. van Os J, Kenis G, Rutten BP: The environment and schizophrenia. Nature 2010, 468:203-212.

\section{FlOOOPrime}

RECOMMENDED

5. D'Souza DC, Perry E, MacDougall L, Ammerman Y, Cooper T, Wu YT, Braley G, Gueorguieva R, Krystal JH: The psychotomimetic effects of intravenous delta-9-tetrahydrocannabinol in healthy individuals: implications for psychosis. Neuropsychopharmacology 2004, 29:1558-1572.

\section{FlOOOPrime} RECOMMENDED

6. Di Forti M, Morrison PD, Butt A, Murray RM: Cannabis use and psychiatric and cogitive disorders: the chicken or the egg? Curr Opin Psychiatry 2007, 20:228-234.

\section{FlOOOPrime \\ RECOMMENDED}

7. Moore TH, Zammit S, Lingford-Hughes A, Barnes TR, Jones PB, Burke M, Lewis G: Cannabis use and risk of psychotic or affective mental health outcomes: a systematic review. Lancet 2007, 370:319-328.

\section{FlOOOPrime} RECOMMENDED

8. Callaghan RC, Cunningham JK, Allebeck P, Arenovich T, Sajeev G, Remington G, Boileau I, Kish SJ: Methamphetamine use and schizophrenia: a population-based cohort study in California. Am J Psychiatry 2012, 169:389-396.

\section{FlOOOPrime}

9. Rossler W, Hengartner MP, Angst J, Ajdacic-Gross V: Linking substance use with symptoms of subclinical psychosis in a community cohort over 30 years. Addiction 2012, I07: | I74-I I 84.

FlOOOPrime

RECOMMENDED

10. Macleod J, Oakes R, Copello A, Crome I, Egger M, Hickman M, Oppenkowski T, Stokes-Lampard H, Davey Smith G: Psychological and social sequelae of cannabis and other illicit drug use by young people: a systematic review of longitudinal, general population studies. Lancet 2004, 363:1579-1588.

II. McGrath J, Welham J, Scott J, Varghese D, Degenhardt L, Hayatbakhsh MR, Alati R, Williams GM, Bor W, Najman JM: Association between cannabis use and psychosis-related outcomes using sibling pair analysis in a cohort of young adults. Arch Gen Psychiatry 2010, 67:440-447.

\section{FlOOOPrime}

RECOMMENDED

12. Fergusson DM, Boden JM, Horwood LJ: Tests of causal links between alcohol abuse or dependence and major depression. Arch Gen Psychiatry 2009, 66:260-266.

\section{FlOOOPrime}

RECOMMENDED

13. Whitaker HJ, Farrington CP, Spiessens B, Musonda P: Tutorial in biostatistics: the self-controlled case series method. Stat Med 2006, 25: 1768-1797.

\section{FlOOOPrime} RECOMMENDED

14. Davey Smith G, Ebrahim S: 'Mendelian randomization': can genetic epidemiology contribute to understanding environmental determinants of disease? Int J Epidemiol 2003, 32: I-22.

\section{FlOOOPrime \\ RECOMMENDED}

15. Lewis SJ, Araya R, Smith GD, Freathy R, Gunnell D, Palmer T, Munafo M: Smoking is associated with, but does not cause, depressed mood in pregnancy-a mendelian randomization study. PLoS One 2011, 6:e21689.

16. Lawlor DA, Davey Smith G, Ebrahim S: Commentary: the hormone replacement-coronary heart disease conundrum: is this the death of observational epidemiology? Int J Epidemiol 2004, 33:464-467.

\section{FlOOOPrime
RECOMMENDED}

17. Phillips AN, Smith GD: Bias in relative odds estimation owing to imprecise measurement of correlated exposures. Stat Med 1992, II:953-96|.

FIOOOPrime

18. Degenhardt L, Hall W, Lynskey M: Testing hypotheses about the relationship between cannabis use and psychosis. Drug Alcohol Depend 2003, 7I:37-48.

\section{FlOOOPrime}

19. Hickman M, Vickerman P, Macleod J, Kirkbride J, Jones PB: Cannabis and schizophrenia: model projections of the impact of the rise in cannabis use on historical and future trends in schizophrenia in England and Wales. Addiction 2007, 102:597-606.

\section{FlOOOPrime}

\section{RECOMMENDED}

20. Gfroerer J, Brodsky M: The incidence of illicit drug use in the United States, 1962-1989. Br J Addict 1992, 87:| |345-|35|. 
21. Frisher M, Crome I, Martino O, Croft P: Assessing the impact of cannabis use on trends in diagnosed schizophrenia in the United Kingdom from 1996 to 2005. Schizophr Res 2009, II3:123-128.

\section{FlOOOPrime \\ RECOMMENDED}

22. Macleod J, Hickman M: How ideology shapes the evidence and the policy: what do we know about cannabis use and what should we do? Addiction 2010, I05:1326-1330.

23. Hall W, Pacula RL: Cannabis use and dependence: public health and public policy. Melbourne: Cambridge University Press; 2003.

24. Hickman M, Vickerman P, Macleod J, Lewis G, Zammit S, Kirkbride J, Jones $\mathrm{P}$ : If cannabis caused schizophrenia-how many cannabis users may need to be prevented in order to prevent one case of schizophrenia? England and Wales calculations. Addiction 2009, 104:|856-|86|.

25. Caspi A, Moffitt TE, Cannon M, McClay J, Murray R, Harrington H, Taylor A, Arseneault L, Williams B, Braithwaite A, Poulton R, Craig IW: Moderation of the effect of adolescent-onset cannabis use on adult psychosis by a functional polymorphism in the catecholO-methyltransferase gene: longitudinal evidence of a gene $X$ environment interaction. Biol Psychiatry 2005, 57: I I 17- I I 27.

\section{FlOOOPRime}

26. Costas J, Sanjuan J, Ramos-Rios R, Paz E, Agra S, Tolosa A, Paramo M, Brenlla J, Arrojo M: Interaction between COMT haplotypes and cannabis in schizophrenia: a case-only study in two samples from Spain. Schizophr Res 20II, 127:22-27.

\section{FlOOOPrime}

\section{RECOMMENDED}

27. Zammit S, Owen MJ, Evans J, Heron J, Lewis G: Cannabis, COMT and psychotic experiences. Br J Psychiatry 20II, 199:380-385.

FlOOOPrime

28. Zammit S, Spurlock G, Williams H, Norton N, Williams N, O'Donovan MC, Owen M]: Genotype effects of CHRNA7, CNR I and COMT in schizophrenia: interactions with tobacco and cannabis use. BrJ Psychiatry 2007, 191:402-407.
29. Di Forti M, Morgan C, Dazzan P, Pariante C, Mondelli V, Marques TR, Handley R, Luzi S, Russo M, Paparelli A, Butt A, Stilo SA, Wiffen B, Powell J, Murray RM: High-potency cannabis and the risk of psychosis. Br J Psychiatry 2009, 195:488-49I.

\section{FlOOOPrime
RECOMMENDED}

30. Zuardi AW, Crippa JA, Hallak JE, Bhattacharyya S, Atakan Z, MartinSantos R, McGuire PK, Guimaraes FS: A critical review of the antipsychotic effects of Cannabidiol: 30 years of a translational investigation. Curr Pharm Des 2012.

\section{FlOOOPrime}

RECOMMENDED

31. Hardwick S, King L: Home Office Cannabis Potency Study 2008. Edited by Office H. St Albans: Home Office Scientific Development Branch; 2008

32. Morgan C], Curran HV: Effects of cannabidiol on schizophrenialike symptoms in people who use cannabis. $\mathrm{Br}$ J Psychiatry 2008, 192:306-307.

\section{FlOOOPrime}

\section{RECOMMENDED}

33. Morgan C], Gardener C, Schafer G, Swan S, Demarchi C, Freeman TP Warrington P, Rupasinghe I, Ramoutar A, Tan N, Wingham G, Lewis S, Curran HV: Sub-chronic impact of cannabinoids in street cannabis on cognition, psychotic-like symptoms and psychological well-being. Psychol Med 201 I:I-10.

\section{FlOOOPrime}

RECOMMENDED

34. Kozlowski LT, O'Connor RJ: Cigarette filter ventilation is a defective design because of misleading taste, bigger puffs, and blocked vents. Tob Control 2002, I I (Suppl I):140-50

\section{FIOOOPrime}

\section{RECOMMENDED}

35. Hurt RD, Robertson CR: Prying open the door to the tobacco industry's secrets about nicotine: the Minnesota Tobacco Trial. JAMA 1998, 280:1 I73-1।81.

36. Strasser AA, Tang KZ, Sanborn PM, Zhou JY, Kozlowski LT: Behavioral filter vent blocking on the first cigarette of the day predicts which smokers of light cigarettes will increase smoke exposure from blocked vents. Exp Clin Psychopharmacol 2009, 17:405-4I2. 